\title{
Precordial R-wave reappearance predicting infarct size and myocardial recovery after acute STEMI
}

\author{
M. T. Rijnierse • N. J. Verouden • R. J. de Winter
}

Published online: 25 May 2011

(C) The Author(s) 2011. This article is published with open access at Springerlink.com

\section{Introduction}

Pathological Q waves may appear on the 12-lead electrocardiogram (ECG) during acute ST-segment elevation myocardial infarction (STEMI) and signify loss of electrical excitation. Anterior wall STEMI often results in loss of $\mathrm{R}$ waves in the precordial leads and subsequent appearance of pathological Q waves. Not infrequently, very early loss of $\mathrm{R}$ waves may be visible in patients presenting with anterior STEMI and occasionally, these $\mathrm{R}$ waves reappear in the first months following the index event. Despite reports in the literature [1-9], the prognostic significance of R-wave reappearance (RWR) in the setting of primary percutaneous coronary intervention (pPCI) remains uncertain. In this report we present two patients with anterior STEMI who underwent uncomplicated pPCI. The follow-up ECGs were indicative of the amount of myocardial recovery after the acute event as shown by cardiovascular magnetic resonance (CMR) imaging.

M. T. Rijnierse $\cdot$ N. J. Verouden $\cdot$ R. J. de Winter Department of Cardiology, Academic Medical Center, University of Amsterdam,

Amsterdam, the Netherlands

\section{R. J. de Winter $(\square)$}

Department of Cardiology, B2-137, Academic Medical Center, Meibergdreef 9, PO box 22660, 1100 DD, Amsterdam, the Netherlands

e-mail: r.j.dewinter@amc.nl

\section{Case report}

Case 1

A 75-year-old man with no prior history of cardiac disease was admitted to our coronary care unit because of acute chest pain with radiation to the left arm accompanied by vegetative symptoms for $3 \mathrm{~h}$. Smoking was the patient's only risk factor for coronary artery disease. The ECG on admission showed ST-segment elevation in leads aVL and $\mathrm{V}_{1}-\mathrm{V}_{4}$ with loss of $\mathrm{R}$ waves in leads $\mathrm{V}_{1}-\mathrm{V}_{3}$ indicating anterior wall STEMI (Fig. 1a). Emergency coronary angiography revealed an occlusion of the left anterior descending (LAD) artery immediately distal to the origin of the first diagonal branch. Uncomplicated PCI with stenting resulted in restoration of TIMI 3 -graded flow approximately $4 \mathrm{~h}$ after symptom onset. Peak CK-MB level was $148 \mu \mathrm{g} / \mathrm{l}$. Post-procedural ECG showed $>50 \%$ ST-segment resolution but persistent loss of $\mathrm{R}$ waves in leads $\mathrm{V}_{1}-\mathrm{V}_{3}$ (Fig. 1b).

Nevertheless, at the outpatient clinic, 1 month after the MI, the first follow-up ECG showed RWR, most evident in leads $\mathrm{V}_{2}-\mathrm{V}_{3}$ (Fig. 1c). At 3 months after the index event, the second follow-up ECG showed persistent RWR in $\mathrm{V}_{1}-\mathrm{V}_{3}$ with higher $\mathrm{R}$-wave voltage amplitude in $\mathrm{V}_{1}-\mathrm{V}_{2}$ as compared with the previously recorded ECGs (Fig. 1d). CMR at 10 months after the index event showed only limited perfusion defects (Fig. 3a). As a result, we did not observe regional wall motion abnormalities and the left ventricular ejection fraction (LVEF) was $62 \%$. 


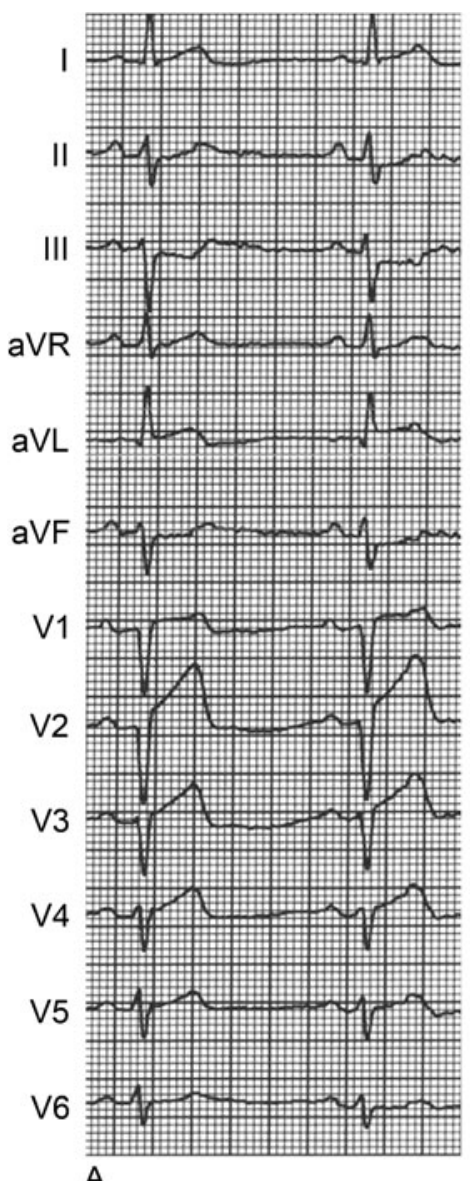

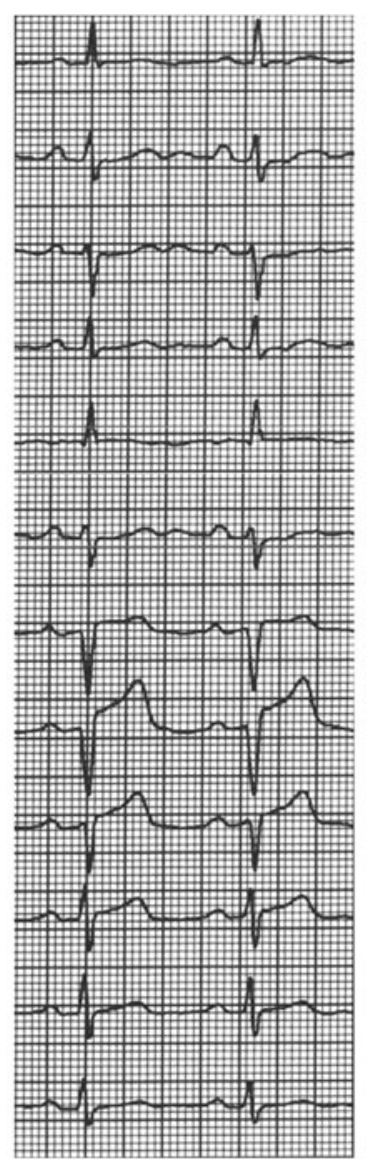

B

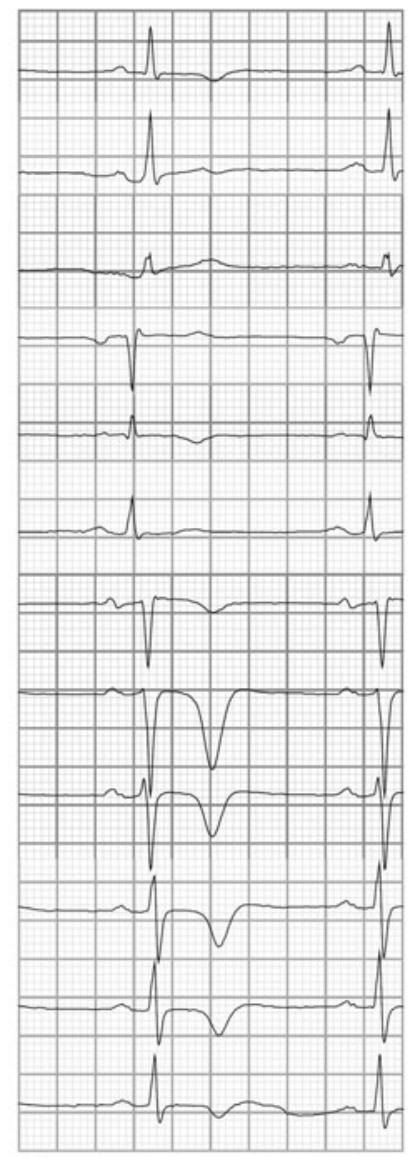

C

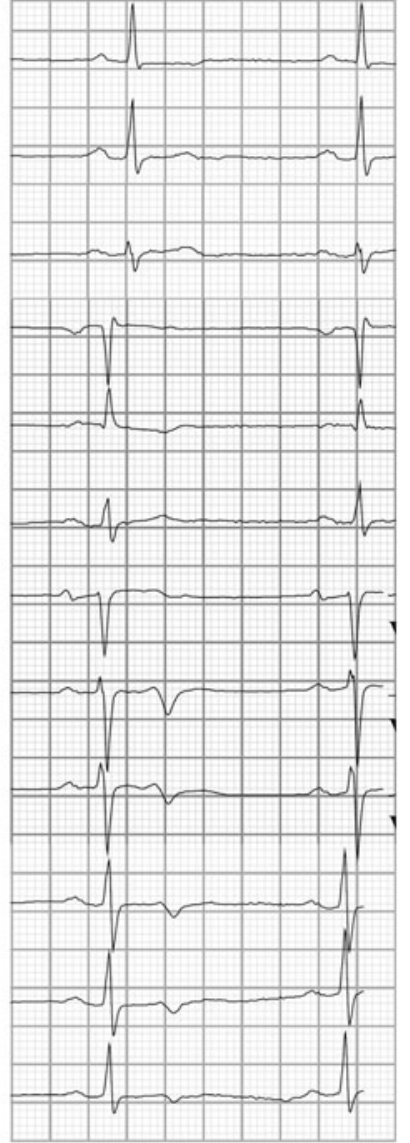

D

Fig. 1 The 12-lead ECG recorded a before primary PCI, b after primary PCI, c after 1 month and $\mathbf{d}$ after 2 months (patient 1)

\section{Case 2}

A 49-year-old man with no prior history of cardiac disease was admitted to our coronary care unit because of typical acute chest pain lasting $3.5 \mathrm{~h}$. The patient's risk factors for coronary artery disease were a positive family history and hypertension. The ECG on admission showed ST-segment elevation in leads aVR, aVL and $\mathrm{V}_{1}-\mathrm{V}_{5}$ with early loss of $\mathrm{R}$ waves in leads $\mathrm{V}_{1}$ and $\mathrm{V}_{2}$ indicating anterior wall STEMI (Fig. 2a). Emergency coronary angiography showed an LAD occlusion immediately distal to the origin of the first diagonal branch. Uncomplicated PCI with stenting resulted in restoration of TIMI-3 graded flow at $4.5 \mathrm{~h}$ after symptom onset. Peak CK-MB was $480 \mu \mathrm{g} / \mathrm{l}$. Post-procedural ECG showed $>50 \%$ ST-segment resolution and R-wave loss in leads $\mathrm{V}_{1}-\mathrm{V}_{2}$ (Fig. 2b).

The follow-up ECGs recorded at 1 week and 4 months after the index event showed persistent $\mathrm{R}$-wave loss
(Fig. 2c, d). CMR showed transmural necrosis of the anteroseptum (Fig. 3b) and LVEF was $45 \%$.

\section{Discussion}

This case report describes two anterior wall STEMI patients with early R-wave loss in the precordial leads. Both patients had a proximal LAD occlusion, and uncomplicated PCI with stenting was performed within $5 \mathrm{~h}$ after symptom onset. Follow-up ECGs in case 1 showed complete RWR, while follow-up ECGs in case 2 showed persistent loss of $\mathrm{R}$ waves. In both cases CMR, performed within 1 year after the index event, showed that the occurrence of RWR was indicative of the amount of myocardial recovery.

RWR is not an uncommon phenomenon in anterior STEMI patients undergoing successful reperfusion therapy. The incidence rates reported in the literature are 39\% and 


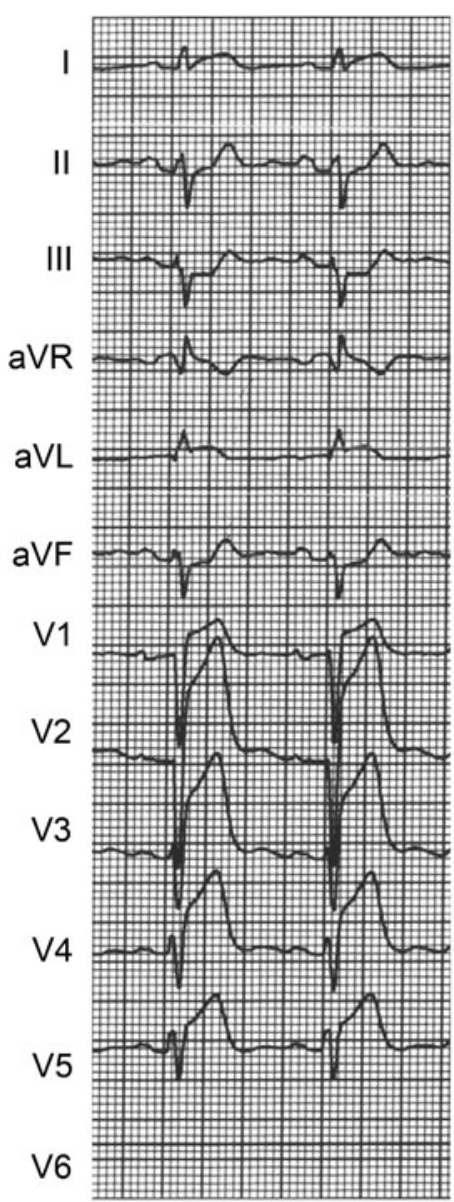

A

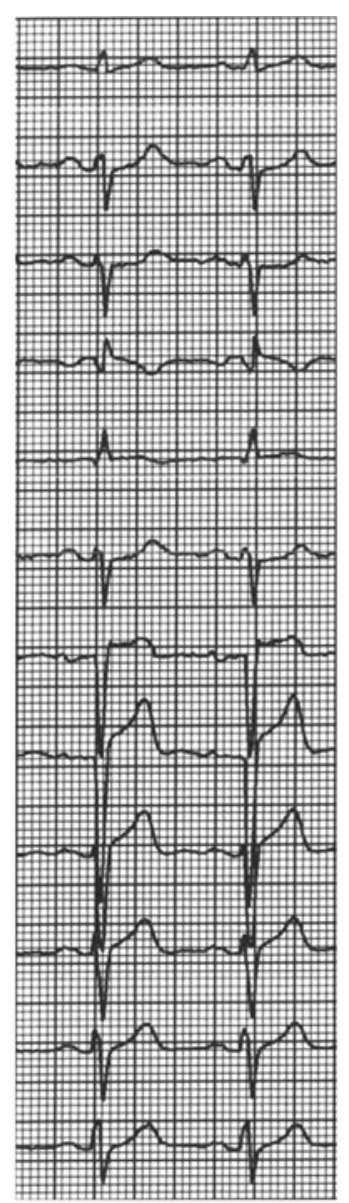

B
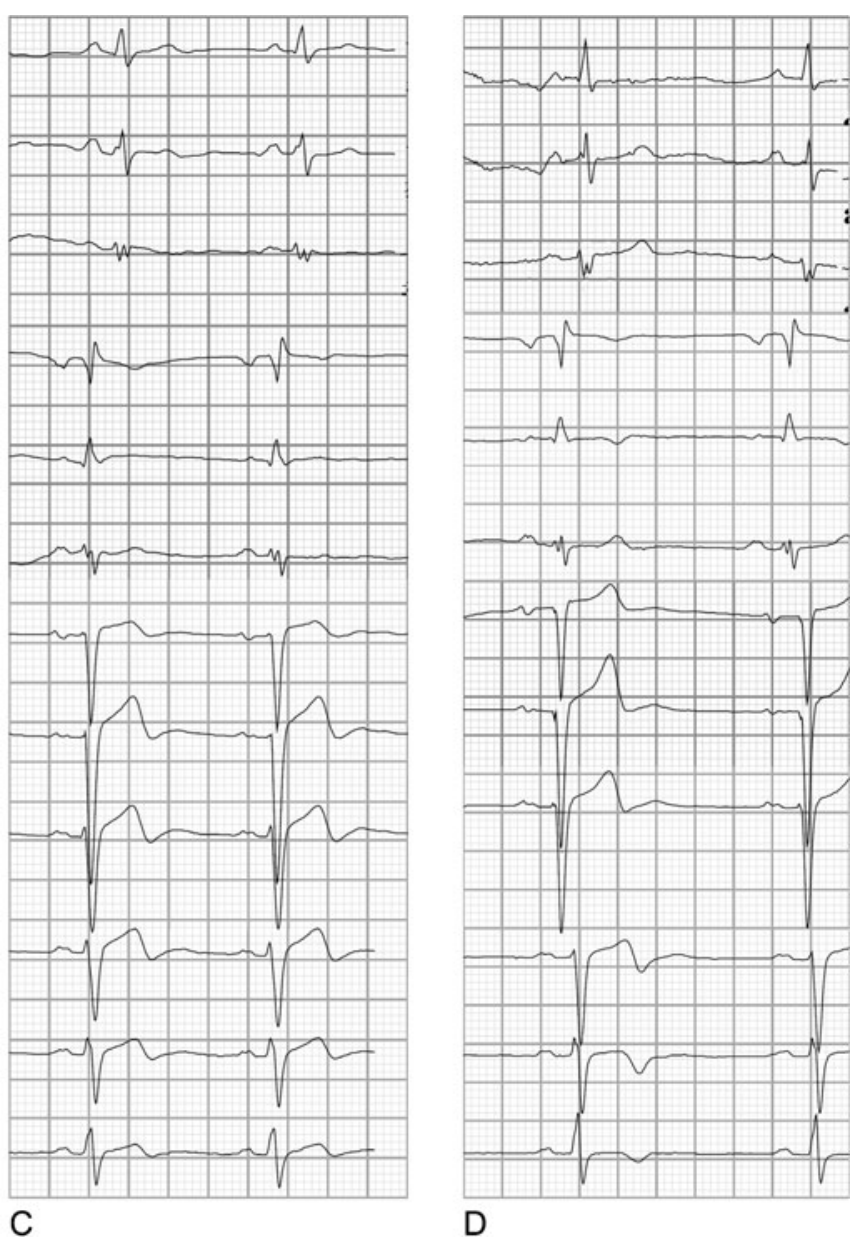

D

Fig. 2 The 12-lead ECG recorded a before primary PCI, b after primary PCI, c after 1 week and $\mathbf{d}$ after 4 months (patient 2)

$77 \%$ during 6 and 6-60 month follow-up periods, respectively $[5,7]$.

The appearance of pathological Q waves in the chronic phase of STEMI has been classically associated with myocardial necrosis, whereas Q waves in the early stages of STEMI may result from a transient loss of electrical function due to intense ischaemia [10]. The exact mechanism of RWR has not been clarified, but the time course may give insight into the mechanism involved in this phenomenon. After the acute phase of STEMI, the infarcted myocardium may gradually shrink as part of the remodelling process. If myocardial fibres are then able to cover the infarcted area, this may result in RWR [11]. However, this process may take several months to years while the RWR in case 1 occurred within 1 month. Bateman et al. [1] explained early RWR by the existence of an 'electrically silent' area in context of myocardial stunning with transient loss of potential in cellular membrane. Finally, the exact position of precordial electrodes could vary during recording of the ECGs influencing R-wave voltage. This seems of minor influence in case 1 as all follow-up ECGs consistently showed complete RWR.

The prognostic significance of RWR remains unclear. Several studies $[2,4,6,7,9]$ reported that patients with RWR had a smaller infarct size and better left ventricular function whereas Iwasaki et al. [5] showed no such association. The CMR in case 1 showed a smaller infarct size and peri-infarct border zone as compared with case 2 . The peri-infarct border zone is postulated to represent a mix of viable and scarred myocardium. This heterogeneous region may act as a substrate for ventricular arrhythmic events which is an indicator of prognosis [12]. In this case, the occurrence of RWR corresponded with a better myocardial recovery revealed by CMR and therefore may provide important prognostic information. 

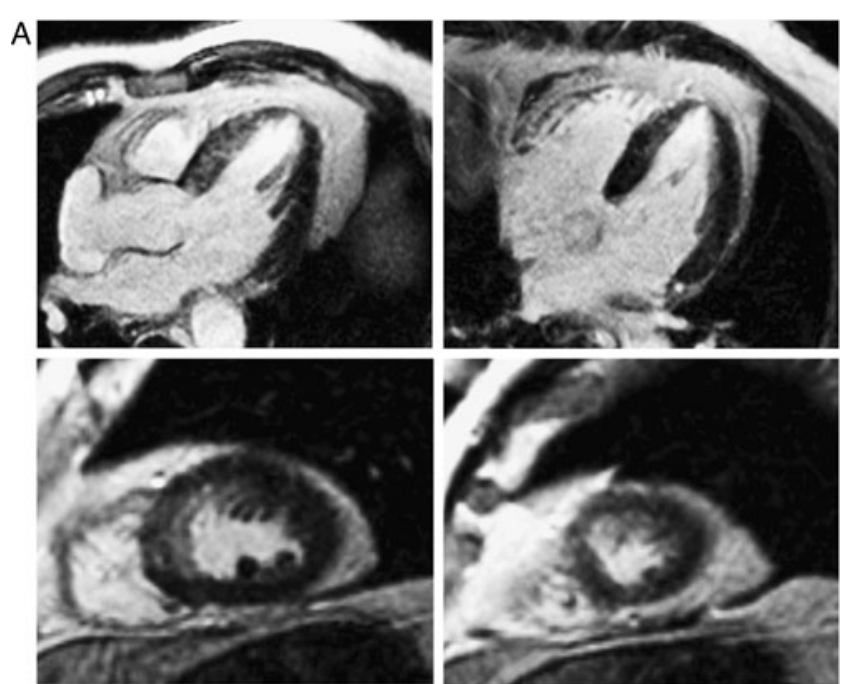

B
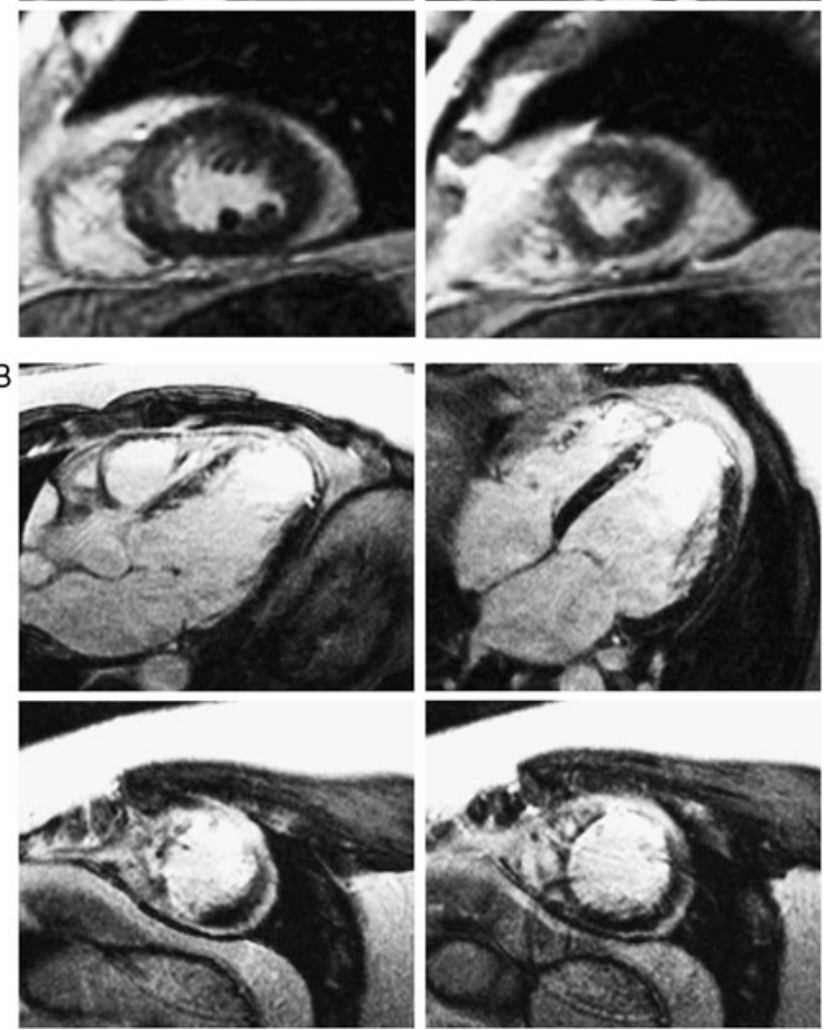

Fig. 3 Cardiovascular magnetic resonance imaging in patient 1 (a) and patient 2 (b). a CMR shows limited perfusion defects. b CMR in shows transmural necrosis of the anteroseptum

By reporting these cases, we would like to create awareness of this phenomenon and encourage future research to enlighten its significance.
Open Access This article is distributed under the terms of the Creative Commons Attribution Noncommercial License which permits any noncommercial use, distribution, and reproduction in any medium, provided the original author(s) and source are credited.

\section{References}

1. Bateman TM, Czer LS, Gray RJ, et al. Transient pathologic Q waves during acute ischemic events: an electrocardiographic correlate of stunned but viable myocardium. Am Heart J. 1983;106(6):1421-6.

2. Coll S, Betriu A, de Flores T, et al. Significance of Q-wave regression after transmural acute myocardial infarction. Am J Cardiol. 1988;61(10):739-42.

3. Haiat R, Chiche P. Transient abnormal Q waves in the course of ischemic heart disease. Chest. 1974;65(2):140-4.

4. Ishikawa K, Shimizu M, Ohno M, et al. Clinical significance of abnormal Q wave disappearance in acute transmural myocardial infarction. Jpn Circ J. 1991;55(3):213-20.

5. Iwasaki K, Kusachi S, Hina K, et al. Q-wave regression unrelated to patency of infarct-related artery or left ventricular ejection fraction or volume after anterior wall acute myocardial infarction treated with or without reperfusion therapy. Am J Cardiol. 1995;76(1):14-20.

6. Jaarsma W, Visser CA, van Eenige MJ, et al. Left ventricular wall motion with and without Q-wave disappearance after acute myocardial infarction. Am J Cardiol. 1987;59(6):516-8.

7. Nagase K, Tamura A, Mikuriya Y, et al. Significance of Q-wave regression after anterior wall acute myocardial infarction. Eur Heart J. 1998;19(5):742-6.

8. Wasserman AG, Bren GB, Ross AM, et al. Prognostic implications of diagnostic $\mathrm{Q}$ waves after myocardial infarction. Circulation. 1982;65(7):1451-5.

9. Yasuda M, Iida H, Itagane $H$, et al. Significance of $Q$ wave disappearance in the chronic phase following transmural acute myocardial infarction. Jpn Circ J. 1990;54(12):1517-24.

10. Atar S, Birnbaum Y. Ischemia-induced ST-segment elevation: classification, prognosis, and therapy. J Electrocardiol. 2005;38(4 Suppl): $1-7$.

11. Kalbfleisch JM, Shadaksharappa KS, Conrad LL, et al. Disappearance of the Q-deflection following myocardial infarction. Am Heart J. 1968;76(2):193-8.

12. Yan AT, Shayne AJ, Brown KA, et al. Characterization of the periinfarct zone by contrast-enhanced cardiac magnetic resonance imaging is a powerful predictor of post-myocardial infarction mortality. Circulation. 2006;114(1):32-9. 